\title{
Phylogeny, Taxonomy, and Biogeography of Pterocarya (Juglandaceae)
}

\author{
Yi-Gang Song ${ }^{1,2,3, *,+}$, Ying Li ${ }^{1,+}$, Hong-Hu Meng ${ }^{4}$, Yann Fragnière ${ }^{2}$, Bin-Jie Ge ${ }^{1} \mathbb{D}$, \\ Hitoshi Sakio ${ }^{5}$, Hamed Yousefzadeh ${ }^{6}$, Sébastien Bétrisey ${ }^{2,7}$ and Gregor Kozlowski $1,2,7, *$ (D) \\ 1 Eastern China Conservation Center for Wild Endangered Plant Resources, \\ Shanghai Chenshan Botanical Garden, Chenhua Road No.3888, Songjiang, Shanghai 201602, China; \\ ying909726271@sina.com (Y.L.); gebinjie123@163.com (B.-J.G.) \\ 2 Department of Biology and Botanic Garden, University of Fribourg, Chemin du Musée 10, \\ CH-1700 Fribourg, Switzerland; yann.fragniere@unifr.ch (Y.F.); sebastien.betrisey@unifr.ch (S.B.) \\ 3 Shanghai Chenshan Plant Science Research Center, Chinese Academy of Sciences, \\ Chenhua Road No.3888, Songjiang, Shanghai 201602, China \\ 4 Centre for Integrative Conservation, Xishuangbanna Tropical Botanical Garden, \\ Chinese Academy of Sciences, Xuefu Rd. 88, Wuhua, Kunming 650223, China; menghonghu@xtbg.ac.cn \\ 5 Field Center for Sustainable Agriculture and Forestry, Faculty of Agriculture, Niigata University, \\ Sado-city, Niigata 950-2181, Japan; sakiohit@gmail.com \\ 6 Faculty of Natural Resources, Department of Forestry, Tarbiat Modares University (TMU), \\ Mazandaran 14115-111, Iran; h.yousefzadeh@modares.ac.ir \\ 7 Natural History Museum Fribourg, Chemin du Musée 6, CH-1700 Fribourg, Switzerland \\ * Correspondence: ygsong@cemps.ac.cn (Y.-G.S.); gregor.kozlowski@unifr.ch (G.K.); \\ Tel.: +86-021-37792288-915 (Y.-G.S.) \\ + These authors contributed equally to this work.
}

Received: 5 October 2020; Accepted: 6 November 2020; Published: 9 November 2020

check for updates

\begin{abstract}
Relict species play an important role in understanding the biogeography of intercontinental disjunctions. Pterocarya (a relict genus) is the valuable model taxon for studying the biogeography of East Asian versus southern European/West Asian disjunct patterns. This disjunction has not been as well studied as others (e.g., between Eastern Asia and North America). Several phylogenetic studies on Pterocarya have been conducted, but none have provided a satisfactory phylogenetic resolution. Here, we report the first well-resolved phylogeny of Pterocarya using restriction site-associated DNA sequencing data based on the sampling of all taxa across the entire distribution area of the genus. Taxonomic treatments were also clarified by combining morphological traits. Furthermore, fossil-calibrated phylogeny was used to explore the biogeography of Pterocarya. Our results support the existence of two sections in Pterocarya, which is in accordance with morphological taxonomy. Section Platyptera comprises three species: P. rhoifolia, P. macroptera, and P. delavayi. Section Pterocarya also comprises three species: $P$. fraxinifolia, $P$. hupehensis, and P. stenoptera. The divergence between the two sections took place during the early Miocene (20.5 Ma). The formation of the Gobi Desert and climate cooling of northern Siberia in the Middle Miocene (15.7 Ma) might have caused the split of the continuous distribution of this genus and the formation of the East Asian versus southern European/West Asian disjunct pattern. Lastly, the divergence between P. hupehensis and P. stenoptera as well as between P. rhoifolia and P. macroptera/P. delavayi (10.0 Ma) supports the late Miocene diversification hypothesis in East Asia.
\end{abstract}

Keywords: divergence time; East Asia-southern Caucasus disjunction; Late Miocene diversification; phylogenomic relationship; refugia; restriction site-associated DNA sequencing (RAD-seq) 


\section{Introduction}

Understanding geographic patterns of species diversity is one of the central aims of biogeography [1-3]. North temperate disjunctions among East Asia, southern Europe/West Asia, eastern North America, and western North America refugia are certainly the best known and most frequently studied of all the major intercontinental disjunctions [1,2,4-7]. Among the northern temperate disjunctions, many analyses have been conducted between (1) East Asia and eastern North America [8-12], (2) East Asia and western North America [13,14], (3) eastern North America and western North America [15], (4) southern Europe and western North America [3,16], and (5) of the trans-Atlantic disjunction [17,18]. There is a group of genera (e.g., Acer, Aesculus, Forsythia, Liquidambar, Picea, Parrotia, Pterocarya, and Zelkova) sharing the East Asian versus southern European/West Asian disjunct pattern, including those in North America [19-22]. However, all these studies ignore the biogeography of East Asia versus southern European/West Asian disjunct patterns.

Relicts are species that were abundant and occurred in a large area at an earlier geological time, but now only occur in one or a few small areas (so called refugia) [7]. The Sino-Japanese Floristic Region (SJFR) in East Asia harbors the most diverse temperate flora worldwide and is the most important glacial refugium for Cenozoic relict flora [23]. Many of the previous phylogeographic studies in the SJFR focused on individual regions, such as the Sino-Himalayan Forest [24-26] and the Sino-Japanese Forest [27-29], as well as on a single species. Hence, the expansion of phylogeographic studies to multiple pairs of sister species or groups of closely related taxa has been advocated [23,28,30,31]. More recently, the late Miocene diversification hypothesis was raised, proposing that the Cenozoic relict flora in East Asia split into southern and northern lineages during the late Miocene [1,2,7,30,32]. However, additional relict genera should be studied in detail to test this hypothesis.

Pterocarya Kunth (Juglandaceae) is a small Cenozoic relict genus whose species live in riparian areas, with six to eight species [33-35]. The members of this genus were widely distributed throughout the Northern Hemisphere during the Miocene, while currently they are limited only to the areas of East Asia and the southern Caucasus (part of West Asia) [36-38]. The disjunct distribution between East Asia (five to seven species) and West Asia (one species) makes Pterocarya a perfect candidate for the exploration of the evolutionary history of genera with disjunct distribution between East Asia and southwestern Eurasia. Additionally, the main distribution in East Asia provides a chance to test the late Miocene diversification hypothesis.

Molecular phylogeny is an important basic framework for biogeography to study the patterns and processes that shape the distributions of life over a wide range of spatial and temporal scales [12,39-41]. Using chloroplast DNA fragments and low-copy nuclear gene data, previous phylogenetic studies on Pterocarya have recovered several provisional frameworks within the genus and identified its position within the Juglandaceae [35,42-45]. The monophyly of Pterocarya is strongly supported, whereas phylogenetic relationships among species in the genus are controversial and remain unresolved (Figure 1A-C). In addition, taxon sampling has not adequately addressed issues related to taxonomic treatments for several taxa. Overall, there are three significant conflicts: (1) the traditional division of the genus into two sections (sect. Platyptera and sect. Pterocarya) is not supported by the current molecular phylogeny; (2) the phylogenetic position of P. hupehensis and P. macroptera is erratic; and (3) there are still controversies on the taxonomic delimitations among closely related Pterocarya species (e.g., three different species mentioned in the Chinese edition of the Flora of China were merged into one taxon (P. macroptera), in contrast to the English edition) [33,34] (Figure 1).

In recent years, phylogenomics has provided a more robust phylogenetic framework, and has breathed new life into biogeography [12]. Restriction site-associated DNA sequencing (RAD-seq) produces abundant single-nucleotide polymorphism (SNP) data throughout the genome, which can be used for phylogenetic inference [46-49]. The RAD-seq approach, in particular, has proven useful in reconstructing fine-scale relationships within closely related species, recently diverged species, and species experiencing interspecific gene flow [41,50-52]. 


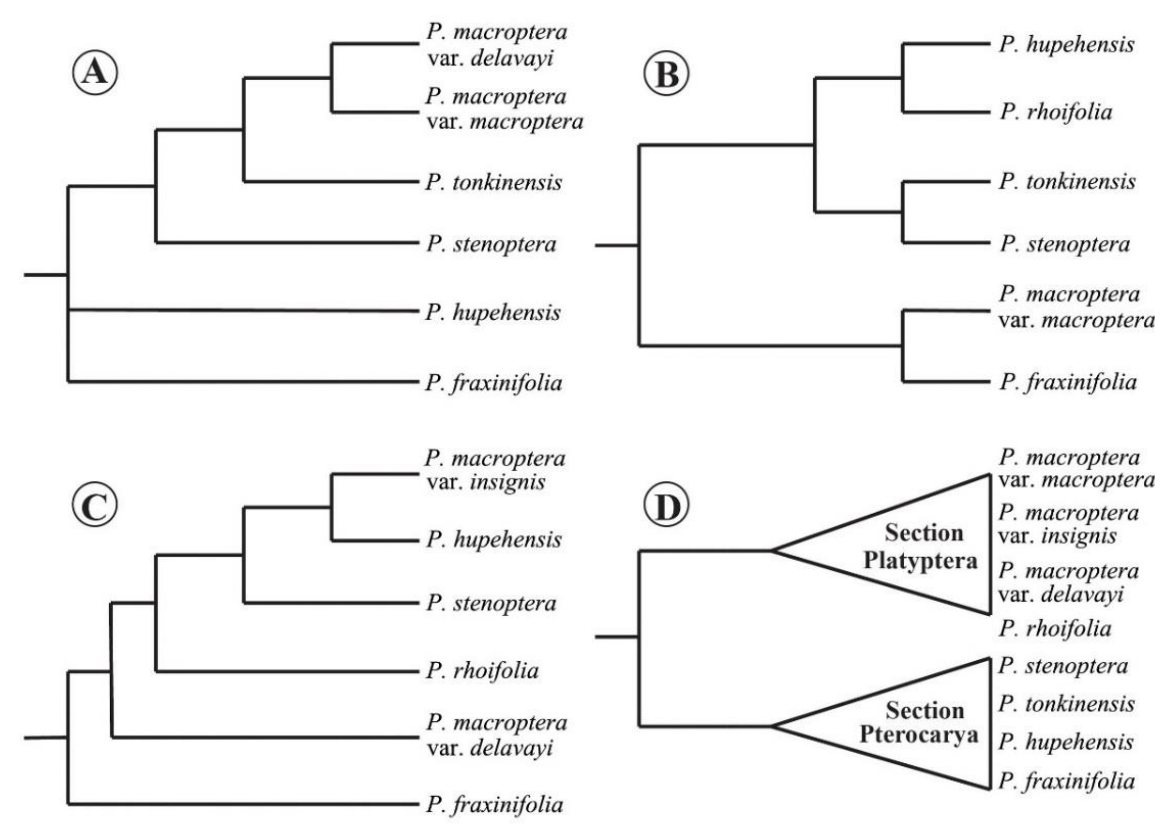

Figure 1. Previous phylogenetic topologies of Pterocarya based on different data sets. (A) Results based on five chloroplast markers $(r b c \mathrm{~L}, m a t \mathrm{~K}, \operatorname{trn} \mathrm{L}, \operatorname{trn} \mathrm{L}-\mathrm{F}$, and $a t p \mathrm{~B}-r b c \mathrm{~L})$ [43]; (B) results based on three chloroplast ( $r b c \mathrm{~L}, m a t \mathrm{~K}$, and $t r n \mathrm{~L}-\mathrm{F}$ ) and two nuclear loci (ITS and Crabs Claw) [44]; (C) results based on nuclear microsatellite and plastid DNA markers [35]; (D) two-section classification interpreted as a phylogenetic hypothesis [34].

The present study aimed to answer the following research questions: (1) What are the stable and well-resolved phylogenetic relationships within the genus Pterocarya? (2) What are the taxonomic treatments based on molecular and morphological analyses? (3) Which biogeographic and speciation events could be responsible for the disjunct distribution of the genus between the East Asian and southwestern Eurasian refugia? (4) Did the sections Platyptera and Pterocarya in the East Asia follow the late Miocene diversification? To address these questions, a comprehensive sample collection strategy was used as well as the following analyses: (1) phylogenetic topology was reconstructed based on RAD-seq data; (2) systematic morphometric analysis was used to clarify taxonomic treatments; and (3) divergence times and biogeographic historical events were estimated based on a fossil-calibrated phylogeny.

\section{Results}

\subsection{RAD-seq and Data Matrices for Phylogenetic Inference}

The Illumina sequencing yielded an average of 11,055,000 reads (raw reads) per sample, ranging from 4,780,000 to 18,580,000. After quality filtering, the average was reduced to 9,947,083 reads (clean reads) per sample, ranging from $3,790,000$ to $17,290,000$. The sequencing quality was high because the average Q30 was $91.54 \%$ per sample, ranging from $88.55 \%$ to $92.39 \%$. The mean GC percentage of all the samples was $47.10 \%$, ranging from $43.03 \%$ to $58.57 \%$ (Table 1). Detailed information concerning the RAD-seq data processing was given in Table S2.

We recovered an average of 5,502,955 reads (RAD tags) after filtering the data de novo via IPYRAD. We obtained 1,728,343 clusters per sample with a mean depth of 15.67. The consensus loci that passed filtering for paralogs ranged from 38,695 to 204,925 , and the average was 102,981 . The mean sequencing error $(E=0.0103)$ was lower than the heterozygosity $(H=0.0413)$. Lastly, the samples had an average of 9287 (ranging from 4222 to 13,650) unlinked SNP sites in the final data sets for phylogenetic inference (Tables 2 and S2). 
Table 1. Summary of RAD-seq data processing (paired-end reads) from 24 samples used in this study.

\begin{tabular}{ccccccc}
\hline Summary Statistic & Raw Reads & Clean Reads & $\begin{array}{c}\text { Total Length of } \\
\text { Clean Reads (Gbp) }\end{array}$ & $\begin{array}{c}\text { Clean Data } \\
\text { Percentage (\%) }\end{array}$ & Q30 Percentage (\%) & GC Percentage (\%) \\
\hline Average & $11,055,000$ & $9,947,083$ & 1.54 & 84.30 & 91.54 & 47.10 \\
Maximum & $18,580,000$ & $17,290,000$ & 2.36 & 90.02 & 92.39 & 58.57 \\
Minimum & $4,780,000$ & $3,790,000$ & 0.69 & 76.16 & 88.55 & 0.88 \\
SD & $3,232,889$ & $3,250,324$ & 0.37 & 3.64 & 3.03 & \\
\hline
\end{tabular}

Table 2. Summary statistics of filtering and clustering results of one single end RAD sequences (R1) from 24 samples used for the phylogenetic analysis in this study.

\begin{tabular}{|c|c|c|c|c|c|c|c|}
\hline Summary Statistic & RAD Tags (R1) & Total Clusters (R1) & Mean Depth of Clusters & $\mathbf{H}$ & E & Consensus Loci & Loci in Final Data Set \\
\hline Average & $5,502,955$ & $1,728,343$ & 15.67 & 0.0413 & 0.0103 & 102,981 & 9287 \\
\hline Maximum & $8,591,043$ & $3,985,579$ & 17.75 & 0.0526 & 0.0136 & 204,925 & 13,650 \\
\hline Minimum & $2,495,755$ & 769,873 & 13.04 & 0.0350 & 0.0075 & 38,695 & 4222 \\
\hline
\end{tabular}

\subsection{RAD-seq Phylogenetic Reconstruction}

Both ML and BI analyses of the final data set showed that the genus Pterocarya is monophyletic with two sections: sect. Pterocarya (which includes P. fraxinifolia, P. hupehensis, P. stenoptera, and P. tonkinensis), and sect. Platyptera (which includes P. rhoifolia and three varieties of P. macroptera) (Figures 2 and S1).

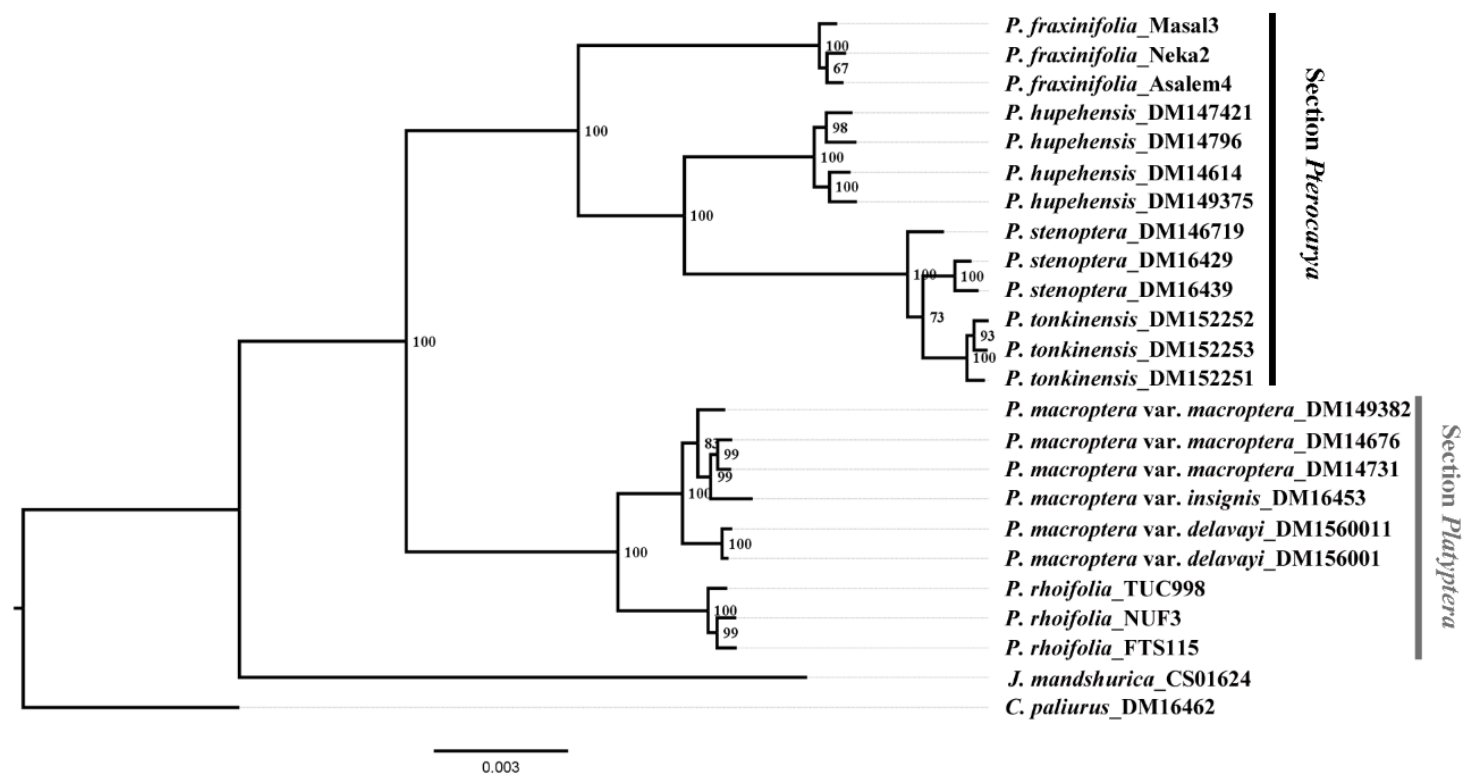

Figure 2. Phylogenetic tree inferred from RAD-seq data for 22 Pterocarya individuals and 2 outgroup taxa using RaxML. The numbers next to the nodes of the binary branches are bootstrap values.

Pterocarya fraxinifolia was sister to the other three species in sect. Pterocarya. Accessions of P. stenoptera were inferred to be paraphyletic, with a population sampled from Zhejiang Province appearing to be more closely related to the accession of P. tonkinensis than to the accessions of P. stenoptera from Shaanxi Province (Figures 2 and S1). Within sect. Platyptera, P. rhoifolia was sister to the clades of P. macroptera. However, the three varieties of P. macroptera, P. macroptera var. delavayi were inferred to be sister to the other two varieties, with $100 \%$ bootstrap (BS) support (Figures 2 and S1).

\subsection{Morphological Traits and Taxonomic Conclusions}

According to the comparative studies of whole morphologies, together with phylogenetic results of the study, there were four main differences between the two sections: (1) terminal buds, which are either naked (sect. Pterocarya) or scaled (sect. Platyptera); (2) presence (sect. Pterocarya) or absence (sect. Platyptera) of lacunae in the walls of the nutlets; (3) presence (sect. Platyptera) or absence (sect. 
Pterocarya) of bud-scale scars on branchlets; and (4) the position of male spikes on old growth (sect. Pterocarya) or new growth (sect. Platyptera). Pterocarya stenoptera and P. tonkinensis were differentiated only by winged and wingless rachises, respectively (Figure 3). With respect to P. macroptera, the mature leaves of the variety delavayi substantially differed from the other two varieties (var. macroptera and insignis), especially regarding the microstructures of the trichomes. The mature leaves of variety delavayi exclusively had solitary trichomes, whereas the other two varieties have fasciculate trichomes scattered along the main and secondary veins (Figures 3 and 4).

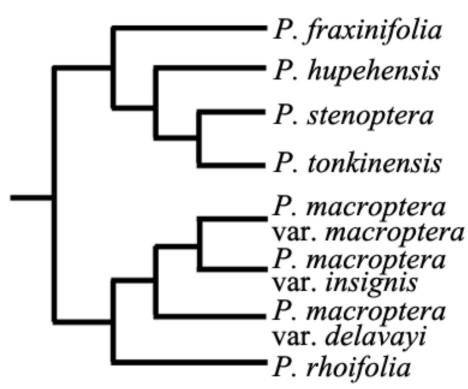

(a): naked (hollow), scaled (solid);

(b), (c), (h), (j): absence (hollow), presence (solid);

(d): old growth (hollow), new growth (solid);

(e): odd (hollow), even (solid);

(f): linear (hollow), semiorbicular (solid);

(g): $<90^{\circ}$ (hollow), approximately $180^{\circ}$ (solid);

(i): 5-13 (hollow), 11-27 (solid);

(k), (1): glabrous (hollow), tomentose (solid);

(m): wingless (hollow), winged (solid).

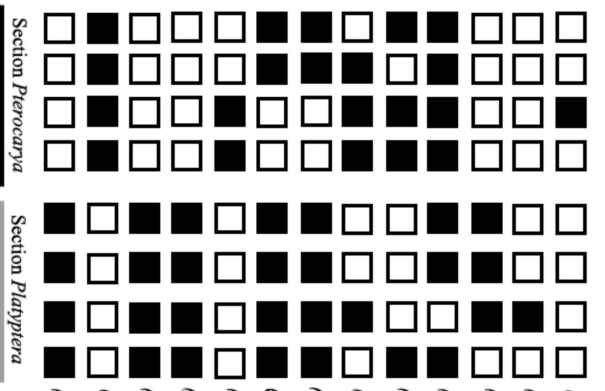

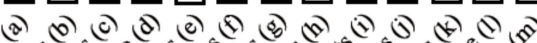

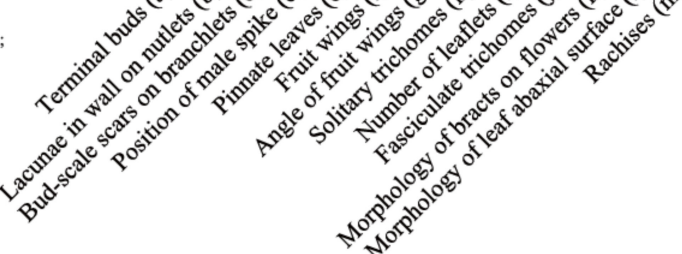

Figure 3. Distribution of taxonomic morphological features in Pterocarya based on new phylogenetic tree.
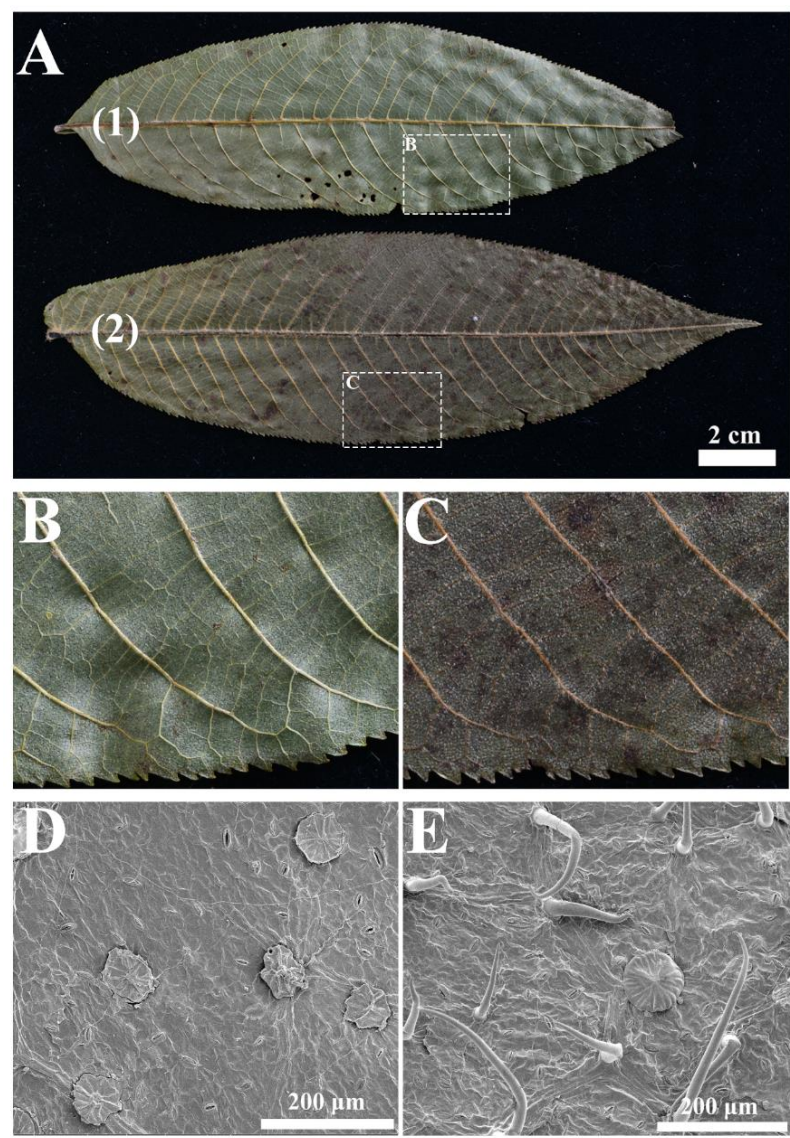

Figure 4. Morphology of leaves of Pterocarya macroptera (A(1),B,D) and Pterocarya delavayi (A(2),C,E). 


\subsection{Estimation of Divergence Times}

The estimated divergence of Pterocarya from Juglans was on the order of $34.73 \mathrm{Ma}$, with $95 \%$ highest posterior density (HPD: 34.0-36.2 Ma). The crown age of Pterocarya with the divergence of the two sections was 20.48 Ma (early Miocene, 95\% HPD: 15.20-27.96 Ma). The estimated crown age of sect. Pterocarya with the divergence of $P$. fraxinifolia from the other species of this section was approximately 15.74 Ma (95\% HPD: 14.16-17.37 Ma). The split between P. hupehensis and the P. stenoptera/P. tonkinensis clade was estimated to have occurred at 9.98 Ma (95\% HPD: 7.73-12.73 Ma). The estimated crown age of sect. Platyptera with the divergence of P. rhoifolia from P. macroptera was approximately $10.17 \mathrm{Ma}$ (95\% HPD: 5.51-14.30 Ma), and the split of P. macroptera var. delavayi from the other two varieties was estimated to have occurred in 5.30 Ma (95\% HPD: 2.41-8.37 Ma) (Figure 5).

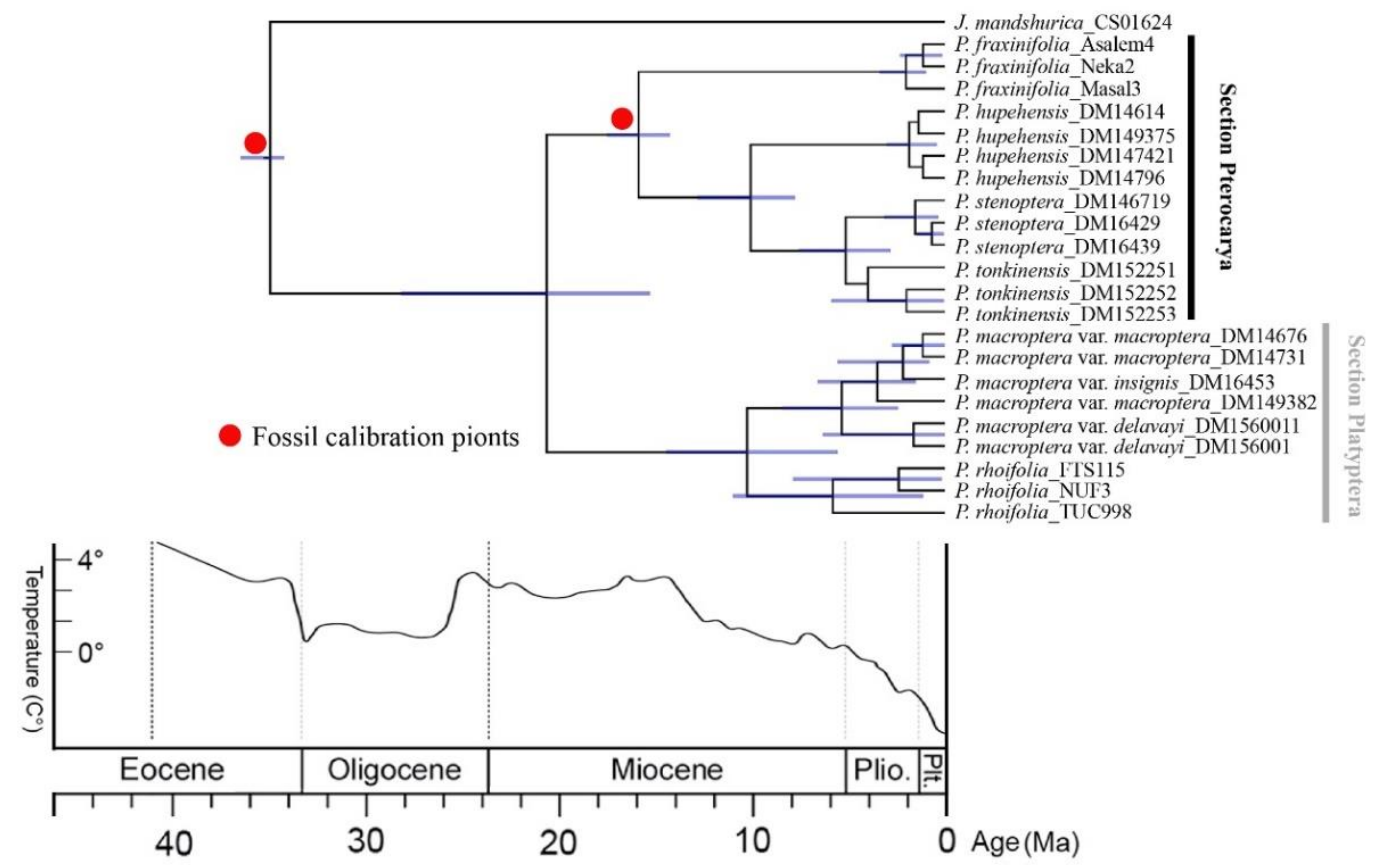

Figure 5. Timing of diversification in Pterocarya. Chronogram derived from a MCC tree estimated via the uncorrelated exponential model in BEAST. The blue bars indicate the 95\% HPD intervals of the age estimate. Geological time abbreviations: Plio. = Pliocene; Plt. = Pleistocene. The climatic sequence of the major global temperature trends was redrawn from that of [53].

\section{Discussion}

\subsection{Phylogenetic Hypothesis for Pterocarya}

We presented a robust phylogenetic reconstruction of Pterocarya based on RAD-seq data. Although there have been previous efforts to understand the phylogenetic and biogeographical history of Pterocarya [35,43-45], no study to date has included all six species and all three varieties of P. macroptera together in a molecular analysis. According to the molecular phylogeny of Xing et al. (2014) [44] in which three chloroplast loci $(r b c \mathrm{~L}, m a t \mathrm{~K}$, and $\operatorname{trn} \mathrm{L}-\mathrm{F})$ and two nuclear loci (internal transcribed spacer [ITS] and Crabs Claw) were used, Pterocarya split into two clades: (1) P. fraxinifolia and P. macroptera var. macroptera clustered into one clade, and (2) the other four species clustered into another clade (Figure 1B). Based on the ITS and trnH-psbA loci, Mostajeran et al. (2016) [45] proposed three clades within Pterocarya: (1) P. fraxinifolia, (2) P. hupehensis and P. macroptera, and (3) P. stenoptera and P. tonkinensis. Xiang et al. (2014) [43] also proposed three clades based on five chloroplast markers $(r b c \mathrm{~L}$, matK, trnL, trnL-F, and atpB-rbcL): (1) P. fraxinifolia; (2) P. hupehensis; and (3) P. stenoptera, P. tonkinensis, P. macroptera var. macroptera, and P. macroptera var. delavayi (Figure 1A). Maharramova et al. (2018) [35] suggested that P. fraxinifolia is the ancestor of the East Asiatic species (Figure 1C) and that P. macroptera 
var. insignis was closely related to P. hupehensis, and thus, that it is more distantly related to P. macroptera var. delavayi (Figure 1C).

Compared with traditional methods, RAD-seq can acquire an abundance of polymorphic markers to solve the problems of few identified gene loci and poor representative genomic information [46-49,54]. Unlike previous studies, our molecular phylogenetic topology showed 100\% support for the separation of the genus Pterocarya into two sections (sect. Pterocarya and sect. Platyptera), which is consistent with the classical taxonomy based on morphological characteristics summarized in Flora of China (FOC) $[33,34]$. Section Pterocarya showed a disjunct distribution between P. fraxinifolia in the Caucasus region and the other three species (P. hupehensis, P. stenoptera, and P. tonkinensis) in East Asia, with $100 \%$ support. Section Platyptera, also with $100 \%$ support, comprises two taxa from East Asia: the Japanese endemic P. rhoifolia and the Chinese endemic P. macroptera. This RAD-seq tree provides a valuable framework for understanding the phylogeny of all species and varieties within the Pterocarya genus.

\subsection{Taxonomic Implications and Evolutionary Importance of Morphological Features}

Taxonomy requires an integrative approach to effectively define species boundaries [55]. Morphological features provide basic information for species identification. Studies on the micromorphology of the genus Pterocarya are lacking, especially concerning the type of trichomes [37]. The present study provides additional identifying characteristics and, for the first time, highlights the importance of trichomes, as well as the morphology of bracts on male and female flowers, for the differentiation of Pterocarya species. When the RAD-seq phylogenetic tree data are combined with the morphological characteristics summarized in FOC [34] and Kozlowski et al. (2018) [37], an in-depth speciation analysis and taxonomic treatment for this genus can be performed.

The species of Pterocarya have a number of unifying characteristics, such as large two-winged nutlets and a chambered pith [37]. Moreover, our study revealed that all the Pterocarya taxa have peltate trichomes (Figure 5). These common features reflect the close affinities among the species and confirm a monophyletic origin of the genus. The presence or absence of terminal buds and lacunae in the nutlet walls provide two main characteristics for differentiating the two sections and thus support the RAD-seq phylogenetic tree. The phylogenetic framework of Pterocarya obtained in this study provides an opportunity to analyze of the evolutionary history of related traits used for the delimitations of different sections and species (Figure 5).

On the basis of our results, we hypothesize that the odd-pinnate leaves represent the ancestral character state, whereas even-pinnate leaves represent the derived character states (Figure 4). Additionally, the close relationship between P. stenoptera and P. tonkinensis is confirmed by only one morphological feature (winged rachises in P. stenoptera but wingless rachises in P. tonkinensis) that virtually differentiates them (Figure 4).

Two micromorphological features are very important for distinguishing P. macroptera from other species, as well as for differentiating among its varieties (Figure 4). First, both female and male flower bracts in all the varieties of this taxon are tomentose, which is exclusive to P. macroptera (all the other species have glabrous bracts). The second important feature is the type of trichomes on mature leaves, which, in P. macroptera var. delavayi, differs from the type of the other two varieties and confirms the phylogenetic resolution within P. macroptera. We have concluded that P. macroptera var. delavayi should be treated morphologically and phylogenetically as a separate species (Pterocarya delavayi). In contrast, the lack of resolution of the phylogenetic tree (Figure 3) and the lack of differences in all the morphological features (Figure 4) suggest that the remaining two varieties (insignis and macroptera) should be merged into one taxon (P. macroptera).

On the basis of these morphological and phylogenetic results, we propose that Pterocarya should be divided into six species: three (P. rhoifolia, P. macroptera, and P. delavayi) in sect. Platyptera and three (P. fraxinifolia, P. hupehensis, and P. stenoptera) in sect. Pterocarya. A new identification key for both sections and all species is provided in the Supplementary Material (Doc. S1). 
3.3. East Asian versus Southern European/West Asian Disjunctions of Relict Trees: The Importance of the Gobi Desert's Formation and Climatic Cooling after the Middle Miocene Epoch

East Asia and southern Europe/West Asia (or southern Caucasus and the Mediterranean regions) served as the most important refugia of relict trees during previous climatic fluctuations $[23,56,57]$. There are many Cenozoic relict woody genera that exhibit the pronounced disjunct distribution patterns between East Asia and southern Europe/West Asia, e.g., Parrotia, Liquidambar, Acer, Albizia, Buxus, Carpinus, Fagus, Diospyros, Hippophae, Sorbus, Taxus, and Zelkova [20,37,58,59]. However, the times and processes leading to the East Asian versus southern European/West Asian disjunct pattern are poorly understood. The results of our study suggest that such a disjunction in the genus Pterocarya (sect. Pterocarya) occurred during the middle of the Miocene period (15.7 Ma), whereas other studies have suggested different divergence times in other relict genera (e.g., 7.5 Ma for the two species of Parrotia in the late Miocene) [20].

The estimated timescale described in our study for the genus Pterocarya is in agreement with the known fossil evidence. Fossil records indicate the wide distribution of this genus in Eurasia during the early Neogene period. The absence of fossil data in western Siberia after the Miocene period indicates the disappearance of Pterocarya during this period. We hypothesize that the local disappearance of Pterocarya in the high latitudes of western Siberia may have been the result of a sharp decrease in global temperatures during the middle Miocene period followed by a major ice sheet expansion from the Arctic [53]. This climatic change may have caused the extinction of Pterocarya, along with other relict woody genera, in large parts of western Eurasia and the formation of the isolated refugium in the southern Caucasus and Hyrcanian forests [37].

The second important event was the desertification of the central Asiatic region and, in particular, the formation of the Gobi Desert. The timing and processes leading to the formation of this desert are still debated [60]. However, recent studies indicate that desertification had already started in the early Miocene period [61-64]. The results of our study support this hypothesis by indicating that biological exchanges between eastern and western Eurasia may have been restricted during the early and middle Miocene periods (Figure 6).
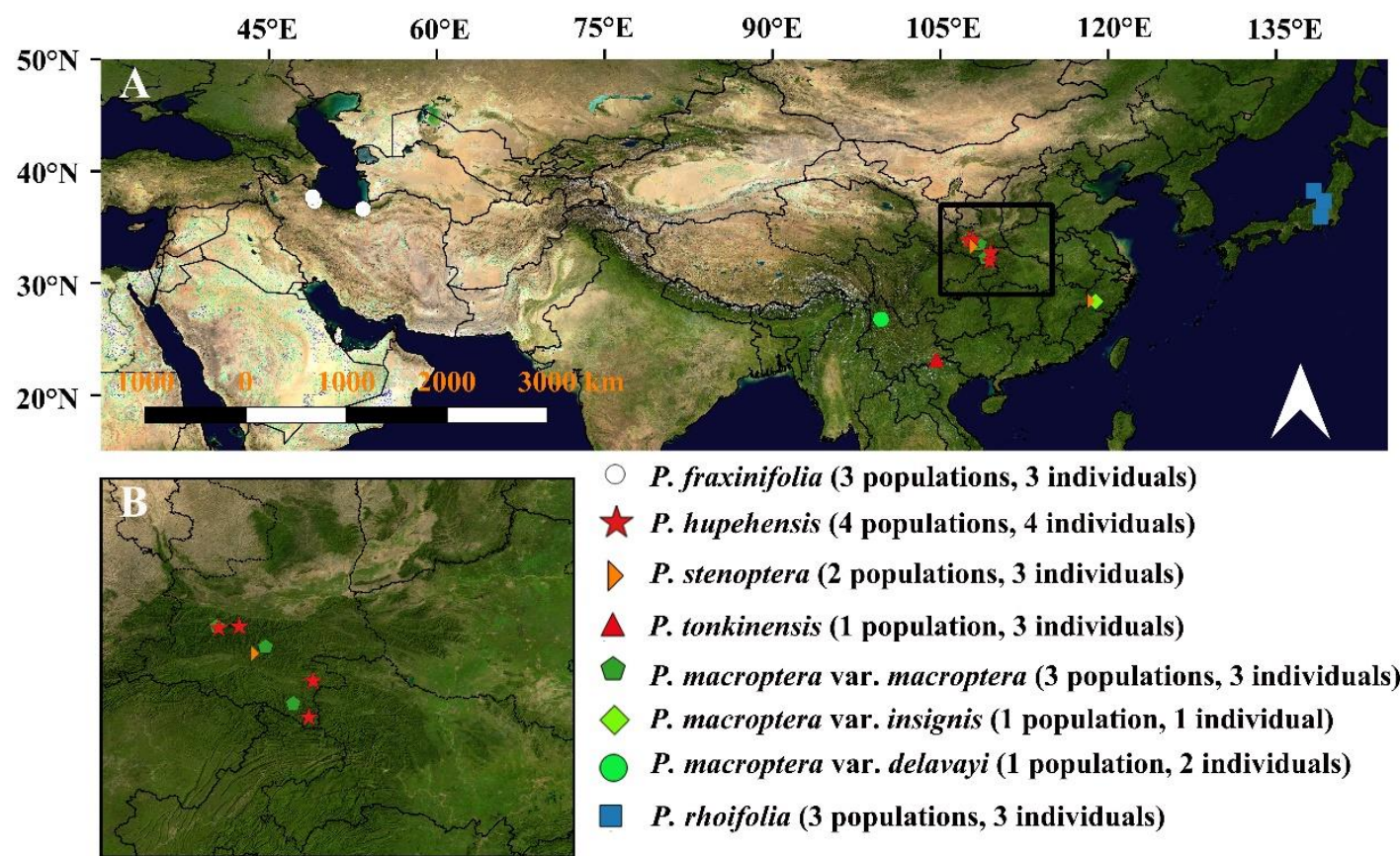
P. fraxinifolia (3 populations, 3 individuals)
$\succsim$ P. hupehensis (4 populations, 4 individuals)
$P$. stenoptera (2 populations, 3 individuals)
$\triangle \quad P$. tonkinensis (1 population, 3 individuals)
P. macroptera var. macroptera (3 populations, 3 individuals)
$\diamond P$. macroptera var. insignis (1 population, 1 individual)
P. macroptera var. delavayi (1 population, 2 individuals)
$\square$ P. rhoifolia (3 populations, 3 individuals)

Figure 6. Sampling sites used in this study covering the entire distribution area of Pterocarya from the southern Caucasus and East Asia. 
In our opinion, these two important climatic and geological events (e.g., cooling of the Siberian region and desertification of Central Asia) could have been responsible for the formation of the current western versus eastern Eurasia disjunct distribution pattern within the Pterocarya genus, as well as in many other relict tree genera, since the middle Miocene period.

\subsection{Late Miocene Diversification in the East Asian Refugium}

With more than 600 endemic genera of the so-called Arcto-Tertiary flora, East Asia is the main refugium for plants, including numerous emblematic relict tree genera and species, such as Gingko, Davidia, and Tetracentron [29]. Toward the late Miocene period, numerous relict tree genera experienced intense diversification and divergence in the region. A prominent example is the split between two species within Cercidiphyllum at the Miocene/Pliocene boundary [29] and the divergence between Chinese Euptelea pleiosperma and Japanese E. polyandra in the late Miocene period (5.5 Ma) [65]. Recently, the same pattern was detected in Asian butternut (Juglans section Cardiocaryon), the sister genus of Pterocarya in Juglandaceae [30]. In addition, our study confirms this biogeographical pattern. In sect. Platyptera, the divergence between P. rhoifolia (endemic to Japan) and P. macroptera (endemic to China) was estimated to have occurred during the late Miocene period (10.17 Ma). These estimated divergence times are very similar to the divergence times of Asian butternuts (10.9 Ma) [30]. The overlapping distributions of $P$. rhoifolia and Juglans ailantifolia in Japan and of P. macroptera and J. cathayensis in China confirm this hypothesis.

Interestingly, in the East Asia, members of the sect. Pterocarya in this genus P. hupehensis diverged from P. stenoptera/P. tonkinensis clade at exactly the same time in the late Miocene period (10.0 Ma). Pterocarya hupehensis is restricted to the mountainous areas of southern East Asia, whereas members of the P. stenoptera/P. tonkinensis clade are widely distributed in eastern and southeastern Asia. The evolutionary history of this clade is clearly in need of further population genetic studies. In the future, new emerging molecular methods (e.g., comparative phylogenomics) based on increased numbers of taxa and sampled populations will help to elucidate the detailed evolutionary and population demographic histories of the genus Pterocarya, as well as other relict genera of the SJFR.

\section{Materials and Methods}

\subsection{Taxon Sampling and DNA Extraction}

In this study, we used twenty-two individuals that represented all species and varieties and covered the entire range of each of the species ( $n$ : number of individuals, $p$ : population number): P. fraxinifolia $(n=3, p=3)$, P. hupehensis $(n=4, p=4)$, P. macroptera var. delavayi $(n=2, p=1)$, P. macroptera var. insignis $(n=1, p=1)$, P. macroptera var. macroptera $(n=3, p=3)$, P. rhoifolia $(n=3, p=3)$, P. stenoptera $(n=3, p=2)$, and P. tonkinensis $(n=3, p=1)$ (Figure 6). Juglans mandshurica and Cyclocarya paliurus were used as outgroups. The voucher specimens are housed in the herbarium of the Shanghai Chenshan Botanical Garden (CSH), at Niigata University, and at Tarbiat Modares University (TMU). None of the field collections of Pterocarya species required specific permissions or involved endangered or threatened species.

DNA extraction was performed with a Qiagen DNeasy Plant Tissue Kit from silica-gel dried leaves according to the manufacturer's (Qiagen, Valencia, CA, USA) standard protocol. The DNA extraction quality was checked by $1 \%$ agarose gel in conjunction with $1 \mathrm{~KB}$ Plus DNA Ladder (Invitrogen) or a New England Biolabs 100 bp DNA ladder marker (Ipswich, MA, USA). The genomic DNA concentrations were subsequently quantified with a dsDNA HS kit on a Qubit 2.0 Fluorometer.

\subsection{RAD-seq Library Preparation}

Library preparation and sequencing of the RAD markers from genomic DNA were performed by Majorbio (Shanghai, China) using the restriction enzyme Taq $\alpha$ I. The Illumina HiSeqTM platform and an Illumina PE150 were used for sequencing, generating 300 500 bp paired-end reads (P1 and P2). 
The restriction sites and barcodes were trimmed from each sequence, and bases with FASTQ quality scores below a given value $(<20)$ were replaced with N. Sequences with more than $10 \%$ of Ns were discarded. Illumina adapters and sequences smaller than $25 \mathrm{bp}$ were removed, and roughly filtered reads of each individual were obtained.

\subsection{Processing and Clustering RAD-seq Data}

After receiving the sequencing data, we demultiplexed and processed the roughly filtered reads using the software pipeline IPYRAD v0.7.11 [66]. Nucleotide bases with a Phred quality score (Q) below 33 were replaced with an ambiguous base ("N"), and reads with more than $5 \%$ " $\mathrm{N}$ "s were discarded. Filtered reads of each individual were first assembled de novo into putative loci. For within-sample clustering, the sequences were clustered at 0.85 similarity by VSEARCH [67]. After clustering, the rates of heterozygosity $(\mathrm{H})$ and sequencing errors $(\mathrm{E})$ were jointly estimated from aligned clusters for each sampled individual [68], and the average parameter values were used when calling consensus bases. Loci containing more than two alleles after error correction were excluded as potential paralogs since Pterocarya species are diploid [42]. Consensus sequences were then aligned with Muscle v3.8.31 [69]. A final filtering step excluded any loci containing one or more sites that appeared heterozygous across more than five samples, as such loci may represent a fixed difference among clustered paralogs rather than a true heterozygous site at the broad phylogenetic scale. The remaining clusters representing multiple alignments of putative orthologs were treated as RAD-seq loci and assembled into phylogenetic data matrices.

\subsection{Morphological Evaluations and Data Sets}

During our fieldwork between 2014 and 2016, we collected all eight taxa of Pterocarya and the two outgroups. Afterwards, we evaluated all the morphological characteristics (including the trunks, bark, buds, leaves, flowers, and fruits) as described in FOC and other publications [33,34,37]. Due to the absence of leaf epidermal features in the literature, we studied the trichomes of all species and varieties of the mature leaves. The dried materials were directly mounted onto stubs without any treatment. After being sputter coated with gold, the specimens were examined and imaged via scanning electron microscopy (SEM) (Quanta 250). The descriptions and terminology of the trichomes mainly followed those of Deng et al. (2014) [70].

We collected data on 13 total binary morphological characteristics: terminal buds (naked or scaled), lacunae in the walls on nutlets (presence or absence), bud-scale scars on branchlets (presence or absence), position of male spike (old or new growth), pinnate leaves (odd or even), fruit wings (linear or semi- or bi-cular), angle of fruit wings $\left(<90^{\circ}\right.$ or approximately $\left.180^{\circ}\right)$, solitary trichomes (presence or absence), number of leaflets (5-13 or 11-27), fasciculate trichomes (presence or absence), morphology of bracts of flowers (glabrous or tomentose), morphology of leaf abaxial surface (glabrous or tomentose), and rachises (wingless or winged). These characteristics were easy to identify and can be treated as binary and were stated on our molecular phylogenetic tree.

\subsection{Phylogenetic Reconstruction}

The single end of the paired-end reads (P1) of RAD-seq data was used for phylogenetic inference and all the data were submitted to GenBank with information related to taxonomy and GenBank accession numbers (Table S1). Maximum likelihood (ML) and Bayesian Inference (BI) trees were inferred using RAxML v8.2.4 [71] and MrBayes v3.2.6 [72], respectively. An ML tree with random starting trees and a GTR + GAMMA nucleotide substitution model was constructed, and the reliability of the tree topology was determined by 200 nonparametric bootstrapped replicates. The BI analyses were started with random trees, and four parallel Markov Chain Monte Carlo (MCMC) searches were performed for 100 million generations each. The trees were sampled every 100 generations, and the first $20 \%$ of each run was discarded as burn-in. Tracer v1.6 [73] was used to check the log-likelihood of sampled trees and determine when stationarity had been reached. 


\subsection{Fossil Constraints and Estimations of Divergence Times}

Two fossils were used as minimum age constraints for two nodes. The first fossil was Juglans clarnensis, which was identified as the oldest Juglans fossil and dated back to the Eocene epoch (34-55 Ma) in North America [36,37]. The second fossil was Pterocarya smileyi from North America. This fossil dated back to the Miocene epoch (5.3-23.0 Ma) and was the first fossil identified as having an affinity with section Pterocarya [36]. To infer divergence times, a relaxed clock model was analyzed under a MCMC simulation in BEAST v1.7.5 [74]. A prior Yule tree was used with an uncorrelated lognormal molecular clock. Tree and log files were generated from two runs with different starting seeds. The MCMC length was 100 million generations, with parameter sampling occurring every 1000 generations. Convergence was assessed by Tracer v1.6 [73], and the effective sample sizes (ESSs) of all the parameters were also assessed. A maximum clade credibility (MCC) tree was generated by TreeAnnotator v1.7.4 after the first $20 \%$ of the trees had been removed as burn-in [74].

Supplementary Materials: The following are available online at http://www.mdpi.com/2223-7747/9/11/1524/s1, Figure S1: Bayesian Inference (BI) tree of Pterocarya. PMM: P. macroptera var. macroptera, PMI: P. macroptera var. insignis, and PMD: P. macroptera var. delavayi, Table S1: List of taxa included in dataset of restriction site-associated DNA sequencing (RAD-seq) for the phylogenetic analysis of Pterocarya with information related to taxonomy and GenBank accession numbers, Table S2: Detail information of RAD-seq data processing for Pterocarya used in this study, Doc. S1: Identification key for the sections and species in the genus Pterocarya (Juglandeceae).

Author Contributions: Conceptualization, G.K. and Y.-G.S.; methodology, Y.L., Y.-G.S., and Y.F.; software, Y.L., B.-J.G, and S.B., and Y.F.; investigation, B.-J.G., H.S., H.Y. S.B., and Y.-G.S.; writing-original draft preparation, Y.-G.S., Y.L., and H.-H.M.; writing—review and editing, G.K., H.S., and H.Y.; supervision, G.K. All authors have read and agreed to the published version of the manuscript.

Funding: This research was funded by (1) Shanghai Municipal Administration of Forestation and City Appearances, grant number G202401; (2) Youth Innovation Promotion Association, CAS in China, grant number 2018432; (3) China Scholarship Council (CSC), grant number 201608310121; and (4) Foundation Franklinia.

Acknowledgments: We would like to thank Duo-Qing Lin and Rui-Bin Liu from Shanghai Chenshan Botanical Garden for their help during the field work.

Conflicts of Interest: The authors declare no conflict of interest.

\section{References}

1. Donoghue, M.J.; Bell, C.D.; Li, J.H. Phylogenetic patterns in Northern Hemisphere plant geography. Int. J. Plant Sci. 2001, 162, S41-S52. [CrossRef]

2. Milne, R.I.; Abbott, R.J. The origin and evolution of tertiary relict floras. Adv. Bot. Res. 2002, 38, 281-314.

3. Mao, K.S.; Hao, G.; Liu, J.Q.; Adams, R.P.; Milne, R.I. Diversification and biogeography of Juniperus (Cupressaceae): Variable diversification rates and multiple intercontinental dispersals. New Phytol. 2010, 188, 254-272. [CrossRef]

4. Raven, P.H. Plant species disjunctions: A summary. Ann. Mo. Bot. Gard. 1972, 59, 234-246. [CrossRef]

5. Thorne, R.F. Major disjunctions in the geographic ranges of seed plants. Q. Rev. Biol. 1972, 47, $365-411$. [CrossRef]

6. Tiffney, B.H. The Eocene North Atlantic land bridge: Its importance in Tertiary and modern phytogeography of the Northern Hemisphere. J. Arnold Arbor. 1985, 66, 243-273. [CrossRef]

7. Milne, R.I. Northern hemisphere plant disjunctions: A window on tertiary land bridges and climate change? Ann. Bot. 2006, 98, 465-472. [CrossRef]

8. Wen, J. Evolution of eastern Asian and eastern North American disjunct distributions in flowering plants. Annu. Rev. Ecol. Evol. Syst. 1999, 30, 421-455. [CrossRef]

9. Wen, J. Evolution of eastern Asian-eastern North American biogeographic disjunctions: A few additional issues. Int. J. Plant Sci. 2001, 162, S117-S122. [CrossRef]

10. Xiang, Q.Y.; Soltis, D.E.; Soltis, P.S.; Manchester, S.R.; Crawford, D.J. Timing the eastern Asian-Eastern North American floristic disjunction: Molecular clock corroborates paleontological estimates. Mol. Phylogenet. Evol. 2000, 15, 462-472. [CrossRef] [PubMed] 
11. Xiang, Q.Y.; Zhang, W.H.; Ricklefs, R.E. Regional differences in rates of plant speciation and molecular evolution: A comparison between eastern Asia and eastern North America. Evolution 2004, 58, 2175-2184. [CrossRef] [PubMed]

12. Wen, J.; Nie, Z.L.; Ickert-Bond, S.M. Advances in biogeography in the age of a new modern synthesis. J. Syst. Evol. 2019, 57, 543-546. [CrossRef]

13. Wu, Z. On the significance of Pacific intercontinental discontinuity. Ann. Mo. Bot. Gard. 1983, 70, 577-590.

14. Wen, J.; Nie, Z.L.; Ickert-Bond, S.M. Intercontinental disjunctions between eastern Asia and western North America in vascular plants highlight the biogeographic importance of the Bering land bridge from late Cretaceous to Neogene. J. Syst. Evol. 2016, 54, 469-490. [CrossRef]

15. Xiang, Q.Y.; Soltis, D.E.; Soltis, P.S. The eastern Asian and eastern and western North America floristic disjunction: Congruent phylogenetic patterns in seven diverse genera. Mol. Phylogenet. Evol. 1998, 10, 178-190. [CrossRef]

16. Wen, J.; Ickert-Bond, S.M. Evolution of the Madren-Tethyan disjunctions and the North and South American amphitropical disjunctions in plants. J. Syst. Evol. 2009, 47, 331-348. [CrossRef]

17. Donoghue, M.J.; Smith, S.A. Patterns in the assembly of temperate forests around the Northern Hemisphere. Philos. Trans. R. Soc. B Biol. Sci. 2004, 359, 1633-1644. [CrossRef]

18. Manchester, S.R. Biogeographical relationships of North American tertiary floras. Ann. Mo. Bot. Gard. 1999, 82, 472-522. [CrossRef]

19. Ickert-Bond, S.M.; Wen, J. Phylogeny and biogeography of Altingiaceae: Evidence from combined analysis of five non-coding chloroplast regions. Mol. Phylogenet. Evol. 2006, 39, 512-528. [CrossRef]

20. Li, J.H.; Tredici, P.D. The Chinese Parrotia: A sibling species of the Persian Parrotia. Arnoldia 2008, 66, 2-9.

21. Li, J.; Stukel, M.; Bussies, P.; Skinner, K.; Lemmon, A.R.; Lemmon, E.M.; Brown, K.; Bekmetjev, A.; Swenson, N.G. Maple phylogeny and biogeography inferred from phylogenomic data. J. Syst. Evol. 2019, 57, 594-606. [CrossRef]

22. Naciri, Y.; Christe, C.; Betrisey, S.; Song, Y.G.; Deng, M.; Garfi, G.; Kozlowski, G. Species delimation in the East Asian species of the relict tree genus Zelkova (Ulmaceae): A complex history of diversification and admixture among species. Mol. Phylogenet. Evol. 2019, 134, 172-185. [CrossRef] [PubMed]

23. Qiu, Y.X.; Fu, C.X.; Comes, H.P. Plant molecular phylogeography in China and adjacent regions: Tracing the genetic imprints of Quaternary climate and environmental change in the world's most diverse temperate flora. Mol. Phylogenet. Evol. 2011, 59, 225-244. [CrossRef]

24. Zhou, Z.; Hong, D.Y.; Niu, Y.; Li, G.D.; Nie, Z.L.; Wen, J.; Sun, H. Phylogenetic and biogeographic analyses of the Sino-Himalayan endemic genus Cyananthus (Campanulaceae) and implications for the evolution of its sexual system. Mol. Phylogenet. Evol. 2013, 68, 482-497. [CrossRef] [PubMed]

25. Kou, Y.X.; Cheng, S.M.; Tian, S.; Li, B.; Fan, D.M.; Chen, Y.J.; Soltis, D.E.; Soltis, P.S.; Zhang, Z.Y. The antiquity of Cyclocarya paliurus (Juglandaceae) provides new insights into the evolution of relict plants in subtropical China since the late Early Miocene. J. Biogeogr. 2016, 43, 351-360. [CrossRef]

26. Du, F.K.; Hou, M.; Wang, W.T.; Mao, K.S.; Hampe, A. Phylogeography of Quercus aquifolioides provides novel insights into the Neogene history of a major global hotspot of plant diversity in south-west China. J. Biogeogr. 2017, 44, 294-307. [CrossRef]

27. Qiu, Y.X.; Guan, B.C.; Fu, C.X.; Comes, H.P. Did glacials and/or interglacials promote allopatric incipient speciation in East Asian temperate plants? Phylogeographic and coalescent analyses on refugial isolation and divergence in Dysosma versipellis. Mol. Phylogenet. Evol. 2009, 51, 281-293. [CrossRef]

28. Qiu, Y.X.; Sun, Y.; Zhang, X.P.; Lee, J.; Fu, C.X.; Comes, H.P. Molecular phylogeography of East Asian Kirengeshoma (Hydrangeaceae) in relation to Quaternary climate change and landbridge configurations. New Phytol. 2009, 183, 480-495. [CrossRef] [PubMed]

29. Qi, X.S.; Chen, C.; Comes, H.P.; Sakaguchi, S.; Liu, Y.H.; Tanaka, N.; Sakio, H.; Qiu, Y.X. Molecular data and ecological niche modelling reveal a highly dynamic evolutionary history of the East Asian Tertiary relict Cercidiphyllum (Cercidiphyllaceae). New Phytol. 2012, 196, 617-630. [CrossRef]

30. Bai, W.N.; Wang, W.T.; Zhang, D.Y. Phylogeographic breaks within Asian butternuts indicate the existence of a phytogeographic divide in East Asia. New Phytol. 2016, 209, 1757-1772. [CrossRef] [PubMed] 
31. Yang, L.Q.; Hu, H.Y.; Xie, C.; Lai, S.P.; Yang, M.; He, X.J.; Zhou, S.D. Molecular phylogeny, biogeography and ecological niche modelling of Cardiocrinum (Liliaceae): Insights into the evolutionary history of endemic genera distributed across the Sino-Japanese floristic region. Ann. Bot. 2017, 119, 59-72. [CrossRef]

32. Ye, J.W.; Bai, W.N.; Bao, L.; Wang, T.M.; Wang, H.F.; Ge, J.P. Sharp genetic discontinuity in the aridity-sensitive Lindera obtusiloba (Lauraceae): Solid evidence supporting the Tertiary floral subdivision in East Asia. J. Biogeogr. 2017, 44, 2082-2095. [CrossRef]

33. Kuang, K.R.; Zheng, S.X.; Li, P.Q.; Lu, A.M. Myricaceae, Juglandaceae and Betulaceae. In Flora of China (Chinese Version); Wu, Z.Y., Ed.; Science Press: Beijing, China, 1979; Volume 21, pp. 21-30.

34. Lu, A.M.; Donald, E.S.; Grauke, L.J. Juglandaceae. In Flora of China; Wu, Z.Y., Raven, P.H., Eds.; Science Press \& Missouri Botanical Garden Press: Beijing, China; St. Louis, MO, USA, 1999; Volume 4, pp. 277-285.

35. Maharramova, E.; Huseynova, I.; Kolbaia, S.; Gruenstaeudl, M.; Borsch, T.; Muller, L.A. Phylogeography and population genetics of the riparian relict tree Pterocarya fraxinifolia (Juglandaceae) in the South Caucasus. Syst. Biodivers. 2018, 16, 14-27. [CrossRef]

36. Manchester, S.R. The Fossil History of the Juglandaceae. Mongraphs in Systematic Botany from the Missouri Botanical Garden; Allen Press: Lawrence, KS, USA, 1987; Volume 21, pp. 1-137.

37. Kozlowski, G.; Betrisey, S.; Song, Y.G. Wingnuts (Pterocarya) and Walnut Family: Relict Trees: Linking the Past, Present and Future; Natural History Museum Fribourg: Fribourg, Switzerland, 2018; pp. 1-59.

38. Song, Y.G.; Fragnière, Y.; Meng, H.H.; Li, Y.; Bétrisey, S.; Corrales, A.; Manchester, S.; Deng, M.; Jasińska, A.K.; Sâm, H.V.; et al. Global biogeographic synthesis and priority conservation regions of the relict tree family Juglandaceae. J. Biogeogr. 2020, 47, 643-657. [CrossRef]

39. Tkach, N.V.; Hoffmann, M.H.; Roser, M.; Korobkov, A.A.; Von Hagen, K.B. Parallel evolutionary patterns in multiple lineages of arctic Artemisia L. (Asteraceae). Evolution 2008, 62, 184-198. [CrossRef]

40. Schwery, O.; Onstein, R.E.; Bouchenak-Khelladi, Y.; Xing, Y.W.; Carter, R.J.; Linder, H.P. As old as the mountains: The radiations of the Ericaceae. New Phytol. 2015, 207, 355-367. [CrossRef]

41. Massatti, R.; Reznicek, A.A.; Knowles, L.L. Utilizing RADseq data for phylogenetic analysis of challenging taxonomic groups: A case study in Carex sect. Racemosae. Am. J. Bot. 2016, 103, 337-347. [CrossRef]

42. Manos, P.S.; Stone, D.E. Evolution, phylogeny, and systematics of the Juglandaceae. Ann. Mo. Bot. Gard. 2001, 88, 231-269. [CrossRef]

43. Xiang, X.G.; Wang, W.; Li, R.Q.; Lin, L.; Liu, Y.; Zhou, Z.K.; Li, Z.Y.; Chen, Z.D. Large-scale phylogenetic analyses reveal fagalean diversification promoted by the interplay of diaspores and environments in the Paleogene. Perspect. Plant Ecol. 2014, 16, 101-110. [CrossRef]

44. Xing, Y.W.; Onstein, R.E.; Carter, R.J.; Stadler, T.; Linder, H.P. Fossils and a large molecular phylogeny show that the evolution of species richness, generic diversity, and turnover rates are disconnected. Evolution 2014, 68, 2821-2832. [CrossRef]

45. Mostajeran, F.; Yousefzadeh, H.; Davitashvili, N.; Kozlowski, G.; Akbarinia, M. Phylogenetic relationships of Pterocarya (Juglandaceae) with an emphasis on the taxonomic status of Iranian populations using ITS and trnH-psbA sequence data. Plant Biosyst. 2016, 151, 1012-1021. [CrossRef]

46. Miller, M.R.; Dunham, J.P.; Amores, A.; Cresko, W.A.; Johnson, E.A. Rapid and cost-effective polymorphism identification and genotyping using restriction site associated DNA (RAD) markers. Genome Res. 2007, 17, 240-248. [CrossRef]

47. Rowe, H.C.; Renaut, S.; Guggisberg, A. RAD in the realm of next-generation sequencing technologies. Mol. Ecol. 2011, 20, 3499-3502. [CrossRef]

48. Hipp, A.L.; Eaton, D.A.R.; Cavender-Bares, J.; Fitzek, E.; Nipper, R.; Manos, P.S. A framework phylogeny of the American oak clade based on sequenced RAD data. PLoS ONE 2014, 9, e93975. [CrossRef]

49. Razkin, O.; Sonet, G.; Breugelmans, K.; Madeira, M.J.; Gomez-Moliner, B.J.; Backeljau, T. Species limits, interspecific hybridization and phylogeny in the cryptic land snail complex Pyramidula: The power of RADseq data. Mol. Phylogenet. Evol. 2016, 101, 267-278. [CrossRef] [PubMed]

50. Eaton, D.A.R.; Ree, R.H. Inferring Phylogeny and Introgression using RADseq Data: An Example from Flowering Plants (Pedicularis: Orobanchaceae). Syst. Biol. 2013, 62, 689-706. [CrossRef] 
51. Cruaud, A.; Gautier, M.; Galan, M.; Foucaud, J.; Saune, L.; Genson, G.; Dubois, E.; Nidelet, S.; Deuve, T.; Rasplus, J.Y. Empirical Assessment of RAD Sequencing for Interspecific Phylogeny. Mol. Biol. Evol. 2014, 31, 1272-1274. [CrossRef]

52. Liu, L.X.; Jin, X.J.; Chen, N.; Li, X.; Li, P.; Fu, C.X. Phylogeny of Morella rubra and its relatives (Myricaceae) and genetic resources of Chinese bayberry using RAD sequencing. PLoS ONE 2015, 10, e0139840. [CrossRef]

53. Zachos, J.; Pagani, M.; Sloan, L.; Thomas, E.; Billups, K. Trends, rhythms, and aberrations in global climate $65 \mathrm{Ma}$ to present. Science 2001, 292, 686-693. [CrossRef]

54. Mu, X.Y.; Tong, L.; Sun, M.; Zhu, Y.X.; Wen, J.; Lin, Q.W.; Liu, B. Phylogeny and divergence time estimation of the walnut family (Juglandaceae) based on nuclear RAD-Seq and chloroplast genome data. Mol. Phylogenet. Evol. 2020, 147, 106802. [CrossRef]

55. Zhang, C.Y.; Low, S.L.; Song, Y.G.; Nurainas; Kozlowski, G.; Do, T.V.; Li, L.; Zhou, S.S.; Tan, Y.H.; Cao, G.L.; et al. Shining a light on species delimitation in the tree genus Engelhardia Leschenault ex Blume (Juglandaceae). Mol. Phylogenet. Evol. 2020, 152, 106918. [CrossRef]

56. Wolfe, J.A. Some aspects of plant geography of Northern Hemisphere during late Cretaceous and Tertiary. Ann. Mo. Bot. Gard. 1975, 62, 264-279. [CrossRef]

57. Kozlowski, G.; Gratzfeld, J. Zelkova-An Ancient Tree: Global Status and Conservation Action; Natural History Museum Fribourg: Fribourg, Switzerland, 2013; pp. 1-60.

58. Ickert-Bond, S.M.; Pigg, K.B.; Wen, J. Comparative infructescence morphology in Liquidambar (Altingiaceae) and its evolutionary significance. Am. J. Bot. 2005, 92, 1234-1255. [CrossRef]

59. Jia, D.R.; Bartish, I.V. Climatic changes and orogeneses in the Late Miocene of Eurasia: The main triggers of an expansion at a continental scale? Front. Plant Sci. 2018, 9, 1400. [CrossRef]

60. Lu, H.Y.; Wang, X.Y.; Wang, X.Y.; Chang, X.; Zhang, H.Z.; Xu, Z.W.; Zhang, W.C.; Wei, H.Z.; Zhang, X.J.; Yi, S.W.; et al. Formation and evolution of Gobi Desert in central and eastern Asia. Earth Sci. Rev. 2019, 194, 251-263. [CrossRef]

61. Bosboom, R.E.; Abels, H.A.; Hoorn, C.; Van den Berg, B.C.J.; Guo, Z.; Dupont-Nivet, G. Aridification in continental Asia after the Middle Eocene Climatic Optimum (MECO). Earth Planet. Sci. Lett. 2014, 389, $34-42$. [CrossRef]

62. Carrapa, B.; DeCelles, P.G.; Wang, X.; Clementz, M.T.; Mancin, N.; Stoica, M.; Kraatz, B.; Meng, J.; Abdulov, S.; Chen, F.H. Tectono-climatic implications of Eocene Paratethys regression in the Tajik basin of central Asia. Earth Planet. Sci. Lett. 2015, 424, 168-178. [CrossRef]

63. Zheng, H.B.; Wei, X.C.; Tada, R.J.; Clift, P.D.; Wang, B.; Jourdan, F.; Wang, P.; He, M.Y. Late Oligocene-early Miocene birth of the Taklimakan Desert. Proc. Natl. Acad. Sci. USA 2015, 112, 7662-7667. [CrossRef]

64. Li, J.X.; Yue, L.P.; Roberts, A.P.; Hirt, A.M.; Pan, F.; Guo, L.; Xu, Y.; Xi, R.G.; Guo, L.; Qiang, X.K.; et al. Global cooling and enhanced Eocene Asian mid-latitude interior aridity. Nat. Commun. 2018, 9, 3026. [CrossRef]

65. Cao, Y.N.; Comes, H.P.; Sakaguchi, S.; Chen, L.Y.; Qiu, Y.X. Evolution of East Asia's Arcto-Tertiary relict Euptelea (Eupteleaceae) shaped by Late Neogene vicariance and Quaternary climate change. BMC Evol. Biol. 2016, 16, 66. [CrossRef]

66. Eaton, D.A.R. PyRAD: Assembly of de novo RADseq loci for phylogenetic analyses. Bioinformatics 2014, 30, 1844-1849. [CrossRef]

67. Rognes, T.; Flouri, T.; Nichols, B.; Quince, C.; Mahé, F. VSEARCH: A versatile open source tool for metagenomics. Peer] 2016, 4, e2584. [CrossRef] [PubMed]

68. Lynch, M. Estimation of nucleotide diversity, disequilibrium coefficients, and mutation rates from high-coverage genome-sequencing projects. Mol. Biol. Evol. 2008, 25, 2409-2419. [CrossRef]

69. Edgar, R.C. Search and clustering orders of magnitude faster than BLAST. Bioinformatics 2010, 26, $2460-2461$. [CrossRef]

70. Deng, M.; Hipp, A.; Song, Y.G.; Li, Q.S.; Coombes, A.; Cotton, A. Leaf epidermal features of Quercus subgenus Cyclobalanopsis (Fagaceae) and their systematic significance. Biol. J. Linn. Soc. 2014, 176, 224-259. [CrossRef]

71. Stamatakis, A. RAxML version 8: A tool for phylogenetic analysis and post-analysis of large phylogenies. Bioinformatics 2014, 30, 1312-1313. [CrossRef]

72. Ronquist, F.; Teslenko, M.; Van der Mark, P.; Ayres, D.L.; Darling, A.; Hohna, S.; Larget, B.; Liu, L.; Suchard, M.A.; Huelsenbeck, J.P. MrBayes 3.2: Efficient Bayesian Phylogenetic Inference and Model Choice Across a Large Model Space. Syst. Biol. 2012, 61, 539-542. [CrossRef] 
73. Rambaut, A.; Brummond, A.T. Tracer v1.5. 2007. Available online: http://tree.bio.ed.ac.uk/software/tracer/ (accessed on 11 October 2019).

74. Drummond, A.J.; Rambaut, A. BEAST: Bayesian evolutionary analysis by sampling trees. BMC Evol. Biol. 2007, 7, 214. [CrossRef]

Publisher's Note: MDPI stays neutral with regard to jurisdictional claims in published maps and institutional affiliations.

(C) 2020 by the authors. Licensee MDPI, Basel, Switzerland. This article is an open access article distributed under the terms and conditions of the Creative Commons Attribution (CC BY) license (http://creativecommons.org/licenses/by/4.0/). 